Article

\title{
Comparative Study on Microencapsulation of Lavender (Lavandula angustifolia Mill.) and Peppermint (Mentha piperita L.) Essential Oils via Spray-Drying Technique
}

\author{
Bissera Pilicheva ${ }^{1,2}$ (D) Yordanka Uzunova ${ }^{2,3}$ and Plamen Katsarov $1,2, *$ (D) \\ 1 Department of Pharmaceutical Sciences, Faculty of Pharmacy, Medical University of Plovdiv, \\ 4002 Plovdiv, Bulgaria; bisera.pilicheva@mu-plovdiv.bg \\ 2 Research Institute at Medical University of Plovdiv (RIMU), 4002 Plovdiv, Bulgaria; \\ yordanka.uzunova@mu-plovdiv.bg \\ 3 Department of Bioorganic Chemistry, Faculty of Pharmacy, Medical University of Plovdiv, \\ 4002 Plovdiv, Bulgaria \\ * Correspondence: plamen.katsarov@mu-plovdiv.bg; Tel.: +359-899040776
}

Citation: Pilicheva, B.; Uzunova, Y.; Katsarov, P. Comparative Study on Microencapsulation of Lavender (Lavandula angustifolia Mill.) and Peppermint (Mentha piperita L.) Essential Oils via Spray-Drying Technique. Molecules 2021, 26, 7467. https: / / doi.org/10.3390/ molecules 26247467

Academic Editors: Natasa Poklar Ulrih, Maria Filomena Filipe Barreiro and Ilja Gasan Osojnik Črnivec

Received: 27 October 2021

Accepted: 7 December 2021

Published: 9 December 2021

Publisher's Note: MDPI stays neutral with regard to jurisdictional claims in published maps and institutional affiliations.

Copyright: (c) 2021 by the authors. Licensee MDPI, Basel, Switzerland. This article is an open access article distributed under the terms and conditions of the Creative Commons Attribution (CC BY) license (https:/ / creativecommons.org/licenses/by/ $4.0 /)$.

\begin{abstract}
Essential oils have been studied for various applications, including for therapeutic purposes. There is extensive literature regarding their properties; however, their low stability limits their application. Generally, the microencapsulation of essential oils allows enhanced stability and enables the potential incorporation in solid dosage forms. Lavender and peppermint oils were encapsulated in microparticles using a spray-drying technique under optimized conditions: $170{ }^{\circ} \mathrm{C}$ temperature, $35 \mathrm{~m}^{3} / \mathrm{h}$ aspiration volume flow, and $7.5 \mathrm{~mL} / \mathrm{min}$ feed flow. Arabic gum and maltodextrin were used as coating polymers individually in varying concentrations from 5 to $20 \%(w / v)$ and in combination. The microparticles were studied for morphology, particle size, oil content, and flowability. The formulated powder particles showed a high yield of 71 to $84 \%$, mean diameter 2.41 to $5.99 \mu \mathrm{m}$, and total oil content of up to $10.80 \%$. The results showed that both the wall material type and concentration, as well as the type of essential oil, significantly affected the encapsulation process and the final particle characteristics. Our study has demonstrated that the encapsulation of lavender and peppermint oils in Arabic gum/maltodextrin microparticles by spray-drying represents a feasible approach for the conversion of liquids into solids regarding their further use in powder technology.
\end{abstract}

Keywords: spray-drying; lavender oil; peppermint oil; microencapsulation; Arabic gum; maltodextrin

\section{Introduction}

Essential oils (EOs) are widely used as natural preservatives, fragrances, or flavors [1-3]. Recently, significant data concerning various therapeutic applications have been compiled, which entails the evaluation of their capacity for incorporation in various delivery systems. Lavender oil, which is generally obtained from a species of the family Lamiaceae (Lavandula angustifolia, L. latifolia, L. stoechas, and L. intermedia), has a variety of cosmetic and therapeutic applications in herbal medicine ranging from relaxation to treating parasitic infections, burns, and insect bites [4-6]. Recent evidence suggests that lavender oil may prove to be effective in the treatment of neurological disorders, such as anxiety, mood instability, convulsions, neurodegenerative disorders, etc. [7]. Peppermint oil, which is obtained from the leaves of Mentha piperita L., Lamiaceae, is a well-known and important phytoproduct widely used in traditional medicine for several thousand years. The chemical composition of peppermint oil has been studied thoroughly in the literature [8]. It has a wide variety of medicinal properties, such as analgesic, anesthetic, antiseptic, astringent, carminative, decongestant, expectorant, stimulant, anti-inflammatory, etc. [9-11]. Lavender and peppermint oil, like most essential oils, consist of volatile components, which is often a cause of instability during formulation and storage mainly due to evaporation or oxidative degradation [12]. 
Microencapsulation is a feasible approach to incorporate liquid substances into carriers, thus protecting the essential oils from decomposition or evaporation and improving their stability. Currently, microencapsulation is widely applied in different industrial fields, such as food, textile, cosmetic, chemical, and pharmaceutical [13]. Among the various microencapsulation approaches, spray-drying represents a simple, flexible, rapid, and low-process-cost technique [14,15]. Spray-drying can be used for thermolabile materials due to its short contact time in the dryer [16]. Moreover, a continuous mode of production is allowed with high encapsulation efficiency and enhanced stability of volatiles. In this method, the material for encapsulation is homogenized with the carrier material and the mixture is fed into a spray-dryer where it is atomized with a nozzle into a fine mist. The hot air encounters the droplets, resulting in the rapid evaporation of the solvent, thus dramatically decreasing the droplet temperature and allowing the instantaneous entrapment of the volatile compound [17]. The main variables in spray-drying that are generally optimized are feeding rate, air inlet temperature, and air outlet temperature. Basically, the morphology of the finished product is related to the drying conditions, which, in turn, affect the wall material robustness and ability to retain the encapsulated material. For the spray-drying of essential oils, the development of a stable coarse formulation of essential oils into the wall material solution is of crucial importance [18]. Emulsion stability is related to the droplet size distribution and the rheological properties of the emulsion. Enhanced emulsion stability because of smaller droplet size is a prerequisite for increased encapsulation efficiency during spray-drying with subsequent high total oil content in the formulated particles [19].

A wide variety of wall materials have been exploited for encapsulation of volatile compounds, including carbohydrates, cellulose derivatives, lipids, some proteins, and gums $[20,21]$. Lavender and peppermint oils have been included in solid particles applying different production techniques using various polymers, such as chitosan, alginate, gelatin, Arabic gum, ethylcellulose, starch, maltodextrin, and albumine [13,22-26]. The choice of a suitable wall material is crucial for the effective encapsulation of the essential oil in the resulting solid particles. The retention capacity of the polymer used is associated mainly with its physical state and its physicochemical characteristics, such as molecular weight, molecular conformation, and chemical functionality [27]. Arabic gum is a heteropolysaccharide with excellent emulsifying and film-forming properties, good ability to produce microsize particles, and low viscosity at high concentration. However, there are studies suggesting that it alone may not be a sufficient wall material for the encapsulation of certain volatiles [26-29]. Arabic gum capsules may show a limited capacity against oxidation because they act as semipermeable membranes and its porosity to oxygen could be a negative factor for the shelf life of the core material [27]. The addition of a second polymer in order to seal the walls of the resulting solid structures could lead to more efficient encapsulation of the essential oil and its longer retention and stabilization in the final powder product. Maltodextrins are considered as suitable capsule sealing agents, especially for spray-drying. They could reduce the hydroscopicity and enhance the flowability of the resulting material [30].

In our previous research, we have established optimum conditions for the formulation of stable emulsions of lavender and peppermint oils regarding stirring rate, oil-to-water ratio, emulsifier concentration, etc. [31]. In this study, we report the preparation of powder formulations of peppermint and lavender oil using Arabic gum and maltodextrin as wall material for further processing into solid dosage forms for oral administration.

The aim of the study was to evaluate the effect of the wall material type and concentration on the essential oil encapsulation process in order to achieve powder product with a high production yield, maximum oil content in the obtained particles, and satisfactory stability. Moreover, the inclusion of two different essential oils in the proposed particle models allows an assessment to be made of how the oil type affects the characteristics of the final powder product. 


\section{Materials and Methods}

\subsection{Materials}

Lavender oil (Ph Eur 9.0), peppermint oil (Ph Eur 9.0), Arabic gum from acacia tree (Ph Eur 9.0), maltodextrin (from maize starch, dextrose equivalent 8.0-15.0), sorbitan monooleate $\left(\operatorname{Span}^{\circledR} 80\right)$, polyoxyethylene sorbitan monooleate (Tween ${ }^{\circledR} 80$ ), and n-hexane were purchased from Sigma-Aldrich, Germany. Analytical standards for gas chromatography analysis ( $\alpha$-pinene, $\beta$-pinene, 3 -octanon, limonene, linalool, camphor, menthone, menthol, menthyl acetate, caryophyllene) were supplied from Supelco Analytical, Germany.

\subsection{Determination of Essential Oils Composition by Gas Chromatography (GC)}

The components of lavender and peppermint oils were determined using gas chromatograph (GC-CP3800 Varian, UK) equipped with an FID detector, CP 8410 auto sampler, and a VF-5ms capillary column $(30 \mathrm{~m} \times 0.25 \mathrm{~mm}$, film thickness $0.25 \mu \mathrm{m})$. Nitrogen was used as the carrier gas at a flow rate $1 \mathrm{~mL} / \mathrm{min}$. The oven temperature program for both lavender and peppermint oils was initiated at $50{ }^{\circ} \mathrm{C}$ and held for $2 \mathrm{~min}$. For peppermint oil, temperature was raised up to $180{ }^{\circ} \mathrm{C}$ at a rate $3{ }^{\circ} \mathrm{C} / \mathrm{min}$ and maintained for $10 \mathrm{~min}$, then raised to $250^{\circ} \mathrm{C}$ at a rate $20^{\circ} \mathrm{C} / \mathrm{min}$ and held $10 \mathrm{~min}$. For lavender oil, temperature was raised to $205^{\circ} \mathrm{C}$ at a rate $3{ }^{\circ} \mathrm{C} / \mathrm{min}$, maintained $10 \mathrm{~min}$, then raised to $250{ }^{\circ} \mathrm{C}$ at a rate $20{ }^{\circ} \mathrm{C} / \mathrm{min}$. The injector and detector temperatures were $250{ }^{\circ} \mathrm{C}$ and $280{ }^{\circ} \mathrm{C}$, respectively; injection mode split, split ratio 1:100; injected volume $1 \mu \mathrm{L}$. The compounds of the oils were identified in terms of their retention times and compared with those of standards; quantification was achieved using peak area calculations.

\subsection{Emulsion Preparation}

Essential oils emulsions were prepared at a final weight of $200 \mathrm{~g}$, containing $2.5 \%(w / w)$ or $5 \%(w / w)$ essential oil, $5 \%(w / w)$ emulsifying blend (Tween ${ }^{\circledR} 80$ and Span ${ }^{\circledR} 80$ taken at predetermined amounts in accordance with the critical HLB value of each essential oil), and polymer solution as aqueous phase. Arabic gum and maltodextrin were used as encapsulating materials. Polymer solutions were prepared by adding a certain amount of polymer into purified water to obtain a final solid content of $10 \%(w / w)$ and $20 \%(w / w)$. The solutions were stirred overnight at $500 \mathrm{rpm}$ to allow complete hydration of molecules. Emulsification was accomplished by the inversion method under constant stirring (ES mechanical stirrer, Velp Scientifica, Usmate, Italy) at $600 \mathrm{rpm}$ for $20 \mathrm{~min}$. A series of eight emulsions at varied oil concentration and encapsulation polymer ratios was developed.

\subsection{Spray-Drying}

Emulsions were spray dried using a B-290 Büchi Mini Spray Drier (Flawil, Switzerland) equipped with a $0.7 \mathrm{~mm}$ diameter nozzle tip hole in open mode. The feed rate and aspirator were set at $7.5 \mathrm{~mL} / \mathrm{min}$ and $35 \mathrm{~m}^{3} / \mathrm{h}$, respectively. The temperature at the entrance of the system was $170{ }^{\circ} \mathrm{C}$.

\subsection{Microparticles Characterization}

\subsubsection{Production Yield}

The production yields of microparticles were calculated using the weight of finally dried microparticles (W1) with respect to the initial amounts of the components used (W2) using the following equation:

$$
\text { Yield }(\%)=\frac{W 1}{W 2} \times 100
$$

\subsubsection{Particles' Average Size}

The microparticles' size was determined by dynamic light scattering using a Nanotrac Wave II instrument (Microtrac, York, PA, USA). The system is equipped with $3 \mathrm{~mW}$ helium/neon laser at $780 \mathrm{~nm}$ wavelength and measures the particle size with noninvasive 
backscattering technology, performing particle size analysis in the range of $0.8 \mathrm{~nm}$ to $6.5 \mu \mathrm{m}$. The samples for analysis were prepared by suspending a small amount of the powder particles in isopropyl alcohol as a dispersing medium. All measurements were performed at 20-s intervals and were repeated three times.

\subsubsection{Shape and Surface Morphology}

Microstructural attributes of the formulated particles were investigated by scanning electron microscopy using Philips SEM 515 (Philips, Eindhoven, The Netherlands). Samples were analyzed after being attached to the SEM stubs and coated with a thin layer of gold in SC7620 Mini Sputter Coater (Quorum Technologies Ltd., Laughton, East Sussex, UK). SEM was performed at $20 \mathrm{kV}$ acceleration voltage and $5000 \times$ magnification.

\subsubsection{Surface Oil Content}

Surface oil content was determined by dispersing $200 \mathrm{mg}$ microparticles (accurately weighed amount) in $2 \mathrm{~mL}$ of hexane for $20 \mathrm{~min}$ under slight stirring. Then, the dispersion was centrifuged at $5000 \mathrm{rpm}$ for $5 \mathrm{~min}$, supernatant was filtered through Chromafil ${ }^{\circledR}$ filter $(0.45 \mu \mathrm{m})$ and analyzed by gas chromatography.

\subsubsection{Total Oil Content}

The total oil content in the microparticles was determined by hydro-distillation of $10 \mathrm{~g}$ of powder in a Clevenger-type apparatus for $3 \mathrm{~h}$ at the boiling range of water and atmospheric pressure. The oil volume, read directly from the oil collection arm, was converted to weight by multiplying by its density $(0.885 \mathrm{~g} / \mathrm{mL}$ for lavender oil and $0.898 \mathrm{~g} / \mathrm{mL}$ for peppermint oil). Determination was carried out in duplicate.

\subsubsection{Encapsulation Efficiency}

The encapsulation efficiency (EE) was calculated as the amount of oil (O1) in the total amount of powder with respect to the initial amount of oil used (O2) as follows:

$$
E E(\%)=\frac{O 1}{O 2} \times 100
$$

\subsubsection{Moisture Content}

The moisture content was determined with the loss on drying method using a moisture analyzer Kern MLB 09/2004, (Kern \& Sohn GmbH, Balingen, Germany) The sample initial weight was $1 \mathrm{~g}$. Moisture content was expressed as a percentage of weight loss.

\subsection{Flowability Testing}

\subsubsection{Angle of Repose ( $\theta)$}

The angle of repose of the formulated powder samples as an indicator of flowability was measured using fixed funnel method at five different measurements. The angle was calculated according to the equation:

$$
\theta=\arctan \frac{h}{r}
$$

where $\theta$ is the angle of repose, $h$ — the height of the cone, $r$-the radius of the cone's base.

\subsubsection{Hausner Ratio (HR)}

The Hausner ratio was determined by measuring both the bulk density and the tapped density of the powder. Five grams of microparticle powder were placed into a $25 \mathrm{~mL}$ graduated cylinder, the bulk volume $\mathrm{V}_{0}$ was measured, and the bulk density $\left(\rho_{0}\right)$ was calculated. The tapped volume $\mathrm{V}_{\mathrm{S}}$ of the powder was determined by tapping the powder 250 times using SVM tapped density tester (Erweka GmBH, Langen, Germany), and the 
tapped density $\left(\rho_{S}\right)$ was calculated likewise. The Hausner ratio was found according to the following equation:

$$
H R=\frac{\rho_{s}}{\rho_{0}}
$$

\subsection{X-ray Powder Diffraction (XRPD)}

X-ray diffraction studies were carried out using powder X-ray diffractometer (D2 Phaser, Bruker AXS GmbH, Karlsruhe, Germany) to get the idea of the physical state of the constituents. Ni-filtered $\mathrm{Cu}$ radiation at $30 \mathrm{kV}$ and $10 \mathrm{~mA}$ was used. The scan angle

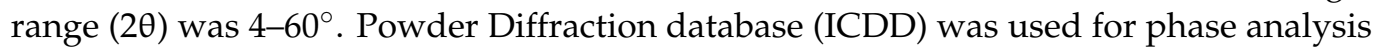
and interpretation of the results.

\section{Results and Discussion}

\subsection{Characterization of Microparticles}

\subsubsection{Production Yield and Encapsulation Efficiency}

Eight models of oil emulsions were prepared at varied wall polymer concentrations $(10 \%$ and $20 \% \mathrm{w} / \mathrm{v})$. To investigate the effect of the type of encapsulating agent, two polymers-Arabic gum and maltodextrin - were used as wall materials individually and in combination at different ratios. The essential oils were emulsified in the polymer solutions prior to spray-drying using additional emulsifying agents-Tween 80 and Span 80 . The composition of the developed emulsions is presented in Table 1.

Table 1. Experimental design of emulsions for spray-drying.

\begin{tabular}{|c|c|c|c|c|c|c|c|c|c|c|}
\hline \multirow[t]{2}{*}{ Sample Code } & \multicolumn{2}{|c|}{$\begin{array}{l}\text { Lavender Oil } \\
\text { (LO) }\end{array}$} & \multicolumn{2}{|c|}{$\begin{array}{l}\text { Peppermint Oil } \\
\text { (PO) }\end{array}$} & \multicolumn{2}{|c|}{$\begin{array}{l}\text { Arabic Gum } \\
\text { (AG) }\end{array}$} & \multicolumn{2}{|c|}{$\begin{array}{l}\text { Maltodextrin } \\
\text { (MD) }\end{array}$} & \multirow{2}{*}{$\begin{array}{c}\text { Tween } \\
80 \\
\mathbf{g}\end{array}$} & \multirow{2}{*}{$\begin{array}{c}\text { Span } \\
80 \\
\mathrm{~g}\end{array}$} \\
\hline & g & $\%$ & g & $\%$ & g & $\%$ & g & $\%$ & & \\
\hline LO-5-AG-20 & 10 & 5 & - & - & 40 & 20 & - & - & 5.33 & 4.67 \\
\hline LO-2.5-AG-10 & 5 & 2.5 & - & - & 20 & 10 & - & - & 5.33 & 4.67 \\
\hline LO-5-AG-MD-15/5 & 10 & 5 & - & - & 30 & 15 & 10 & 5 & 5.33 & 4.67 \\
\hline LO-5-AG-MD-10/10 & 10 & 5 & - & - & 20 & 10 & 20 & 10 & 5.33 & 4.67 \\
\hline LO-5-AG-MD-5/15 & 10 & 5 & - & - & 10 & 5 & 30 & 15 & 5.33 & 4.67 \\
\hline LO-5-MD-20 & 10 & 5 & - & - & - & - & 40 & 20 & 5.33 & 4.67 \\
\hline PO-5-AG-20 & - & - & 10 & 5 & 40 & 20 & - & - & 7.48 & 2.52 \\
\hline PO-2.5-AG-10 & - & - & 5 & 2.5 & 20 & 10 & - & - & 7.48 & 2.52 \\
\hline
\end{tabular}

The obtained stable emulsions were subjected to spray-drying in a Buchi mini spray drier apparatus under pre-optimized conditions $\left(170{ }^{\circ} \mathrm{C}\right.$ inlet temperature, $35 \mathrm{~m}^{3} / \mathrm{h}$ aspiration volume flow, and $7.5 \mathrm{~mL} / \mathrm{min}$ feed flow). The yield of the resulting microparticles was from $71 \%$ to $84 \%$, which could be considered plausible for that preparation method. A slight tendency for increased production yields was observed at higher polymer concentrations, but the effect was insignificant. Using maltodextrin at concentrations above $5 \%$ had a slightly greater impact on production yields. Similar results were reported by other research groups, which have also added maltodextrins to reduce the hygroscopicity of the product and thus prevent stickiness and deposition of the material on the wall of the spray-dryer chamber [32-35]. Maltodextrins are considered to be suitable for spray-drying due to the high solubility, which allows a high degree of incorporation into the feeding solution and, therefore, requires less water removal. The addition of maltodextrin not only improves the drying rate but also enhances powder flowability [30]. There were small differences in the production yields between the samples encapsulating lavender and peppermint essential oils, which were not considered significant.

The estimated encapsulation efficiency of the formulated microparticles was in the range from $19.77 \%$ to $91.08 \%$ (Table 2). That parameter was significantly influenced by the wall material concentration. By increasing the concentration of the polymer used from $10 \%$ to $20 \%$, the encapsulation efficiency increased from $26.53 \%$ to $91.08 \%$ for the 
models with lavender oil and from 19.77 to $54.83 \%$ for the models with peppermint oil. The higher polymer concentration was required for higher oil retention in the particles and more efficient encapsulation. From the models, formulated with a combination of the two polymers, the microparticles LO-5-AG-MD-15/5 (Arabic gum and maltodextrin in a ratio 3:1) showed the highest encapsulation efficiency of $47.15 \%$.

Table 2. Characterization of the microparticles prepared at varied wall material type and concentration ( $\mathrm{LO}=$ lavender oil, $\mathrm{PO}=$ peppermint oil, $\mathrm{AG}=$ Arabic gum, $\mathrm{MD}=$ maltodextrin; $n=3$ ).

\begin{tabular}{|c|c|c|c|c|c|c|}
\hline Sample Code & Wall Material & $\begin{array}{c}\text { Wall Material } \\
\text { Concentration, } \\
\%\end{array}$ & $\begin{array}{c}\text { Production } \\
\text { Yield, } \\
\% \pm \text { SD }\end{array}$ & $\begin{array}{c}\text { Mean Particle } \\
\text { Size, } \\
\mu \mathrm{m} \pm \text { SD }\end{array}$ & $\begin{array}{l}\text { Total Oil } \\
\text { Content, } \\
\% \pm \mathrm{SD}\end{array}$ & $\begin{array}{c}\text { Encapsulation } \\
\text { Efficiency } \\
\% \pm \text { SD }\end{array}$ \\
\hline LO-5-AG-20 & AG & 20 & $76.45 \pm 2.03$ & $5.93 \pm 0.18$ & $10.62 \pm 0.72$ & $48.72 \pm 0.53$ \\
\hline LO-2.5-AG-10 & AG & 10 & $71.37 \pm 1.87$ & $3.15 \pm 0.12$ & $5.31 \pm 0.91$ & $26.53 \pm 0.95$ \\
\hline LO-5-AG-MD-15/5 & AG/MD 75/25 & 20 & $74.01 \pm 0.98$ & $4.84 \pm 0.14$ & $10.55 \pm 1.12$ & $47.15 \pm 1.11$ \\
\hline LO-5-AG-MD-10/10 & AG/MD 50/50 & 20 & $83.05 \pm 1.23$ & $5.99 \pm 0.22$ & $8.85 \pm 0.57$ & $44.10 \pm 1.02$ \\
\hline LO-5-AG-MD-5/15 & $\mathrm{AG} / \mathrm{MD} 25 / 75$ & 20 & $81.03 \pm 1.92$ & $2.41 \pm 0.09$ & $7.08 \pm 1.02$ & $34.42 \pm 0.97$ \\
\hline LO-5-MD-20 & MD & 20 & $84.33 \pm 0.85$ & $3.84 \pm 0.21$ & $10.80 \pm 1.71$ & $91.08 \pm 1.78$ \\
\hline PO-5-AG-20 & AG & 20 & $76.37 \pm 1.48$ & $3.32 \pm 0.08$ & $7.18 \pm 0.65$ & $54.83 \pm 1.53$ \\
\hline PO-2.5-AG-10 & AG & 10 & $73.77 \pm 0.97$ & $3.15 \pm 0.07$ & $1.34 \pm 0.46$ & $19.77 \pm 0.61$ \\
\hline
\end{tabular}

\subsubsection{Particle Shape, Size, and Surface Morphology}

The obtained particles were first visualized using an optical microscope (micrographs not shown). Light microscopy revealed that the particles were spherical in shape and tended to aggregate. The average particle diameter was determined using dynamic light scattering, and it varied in the range of $2.41 \pm 0.09$ to $5.99 \pm 0.22 \mu \mathrm{m}$ (Table 2). The average particle size is generally determined by the process variables, such as drying conditions, method of atomization, concentration, and viscosity of the feeding solution [36].

The scanning electron microscopy showed that the surface of the different models' $\mathrm{mi}$ croparticles was heavily grooved with multiple indentations to varying degrees (Figure 1). Numerous pores were found (samples LO-5-AG-20 and LO-2.5-AG-10), with a slight tendency to smoothen the capsule surface when maltodextrin was added to the polymer solution (samples LO-5-AG-MD-15/5, LO-5-AG-MD-10/10, and LO-5-AG-MD-5/15). This gave us the reason to assume that the models containing a combination of the two polymers tend to retain the encapsulated oil in their core for a longer time, which is a prerequisite for achieving a stabilizing effect. These assumptions were later confirmed by a storage stability test. The sample LO-5-MD-20 that contained maltodextrin as the only encapsulating polymer revealed a much smoother surface without pores and cracks. Therefore, particle morphology is mainly governed by the concentration of maltodextrin in the feeding emulsion. The mixing of Arabic gum with maltodextrin resulted in favorable particle characteristics probably due to the decreased viscosity of the feeding emulsion. Generally, an ideal wall material should have an optimum film forming property and emulsifying ability. The low viscosity of the feeding liquid is essential for the emulsion stability and evaporation rate, ensuring the rapid solidification of the droplets and obtaining smoother particle surface. In the samples with encapsulated peppermint oil (samples PO-5-AG-20 and PO-2.5-AG-10), there were serious deformations in the shape of the particles, which were much more pronounced in the sample PO-2.5-AG-10. The microparticles obtained at a lower polymer concentration $(10 \%)$ presented rough and uneven surfaces, suggesting that the wall is unable to prevent the penetration of the encapsulated oil and assure nucleus protection. From the obtained result, we could suppose that Arabic gum is not capable of forming continuous stable film around the oil droplets before the drying process. This correlates with the unsatisfactory results in terms of the content of essential oil in the polymer structures. 

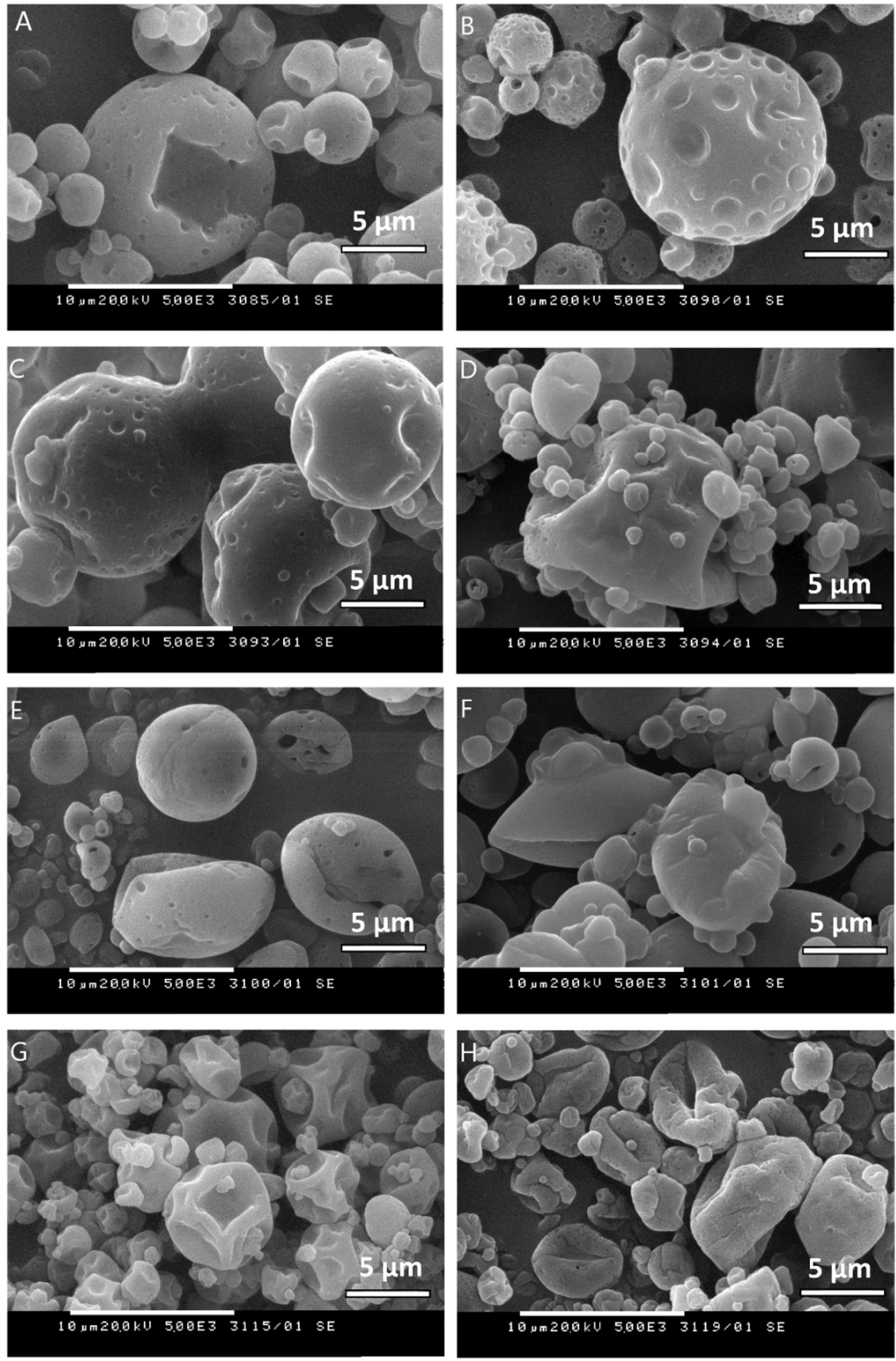

Figure 1. SEM micrographs of the spray dried samples: LO-5-AG-20 (A), LO-2.5-AG-10 (B), LO-5AG-MD-15/5 (C), LO-5-AG-MD-10/10 (D), LO-5-AG-MD-5/15 (E), LO-5-MD-20 (F), PO-5-AG-20 (G), PO-2.5-AG-10 (H), magnification 5000×.

\subsection{XRD Analysis}

The X-ray diffraction results indicated that the controls (Arabic gum and maltodextrin) and the samples (microparticles of lavender and peppermint oils) had similar profiles, characteristic of an amorphous structure. No diffraction maxima of crystalline phases were found in the samples (Figure 2). An intense broad peak was recorded in all the samples, probably due to the presence of coherently scattering domains (structural blocks). The diffraction patterns of the samples were similar, suggesting that the type of the encapsulated oil and the wall materials ratio did not affect the structure of the developed microparticles. 

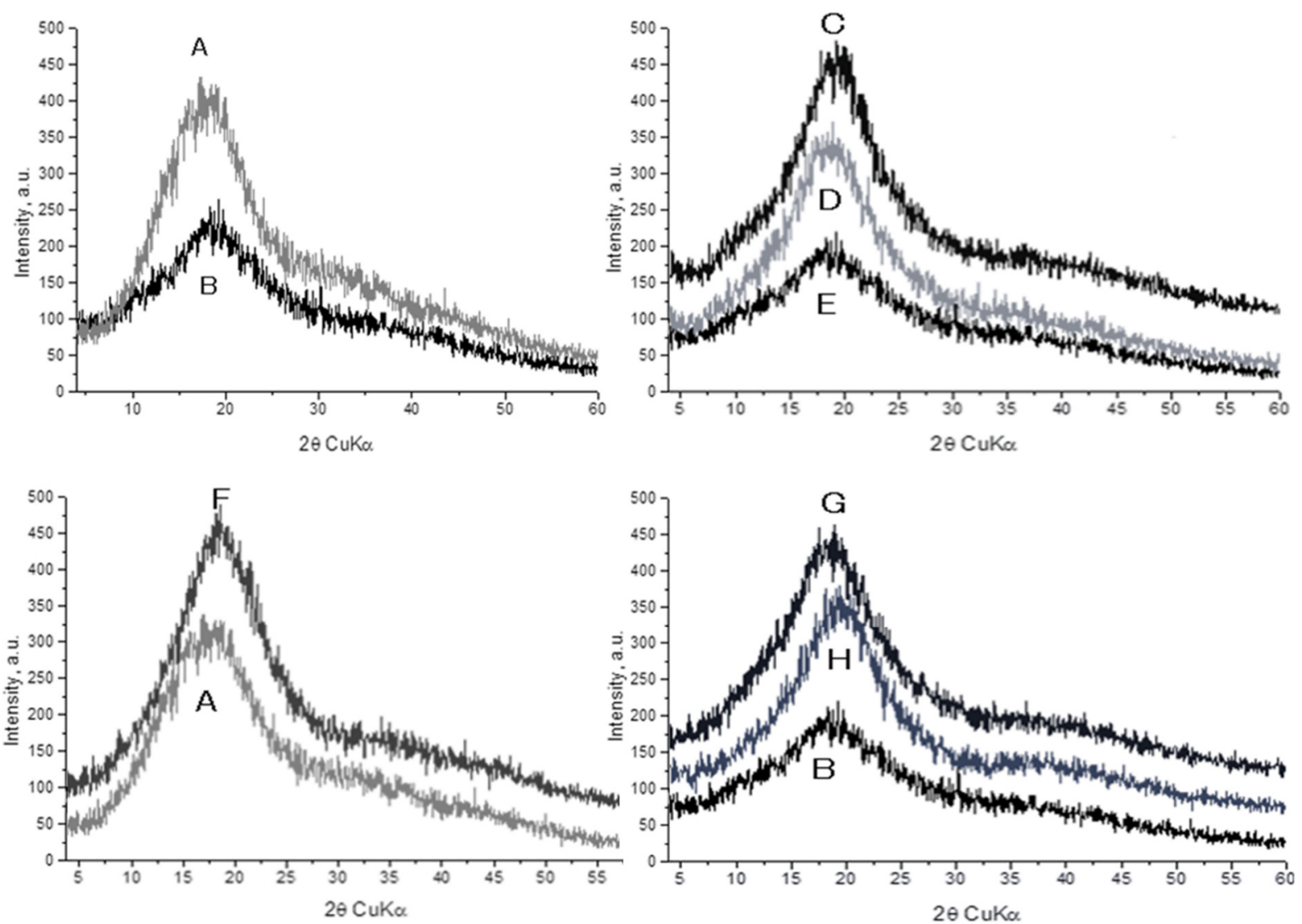

Figure 2. XRD spectra of the raw materials and the formulated samples: maltodextrin (A), Arabic gum (B), LO-2.5-AG-10 (C), LO-5-AG-20 (D), LO-5-AG-MD-10/10 (E), LO-5-MD-20 (F), PO-5-AG-20 (G), PO-2.5-AG-10 (H).

\subsection{Total Oil Content}

The percentage of total oil in the formulated polymer microparticles varied from $1.34 \%$ to $10.80 \%$ (Table 2), indicating that the evaluated parameter was significantly affected by the wall material type (Arabic gum, maltodextrin, or their combination) and its concentration $(10 \%$ or $20 \%)$. Higher oil retention values were observed at high content of solids $(20 \%)$ compared to samples prepared at $10 \%$ wall material concentration. A tendency to reduce the amount of essential oil encapsulated in the particles was observed when a lower concentration of wall polymers was used. A polymer concentration of $10 \%$ was insufficient to effectively retain the essential oil in the particles, probably due to the evaporation of the oil during the spray-drying process. The concentration of wall materials in the feeding solution for spray-drying is directly related to the viscosity of the medium, which, in turn, affects the total oil content retained in the particles. Numerous studies suggested that there should be optimum concentrations of each wall material to achieve the maximum retention of volatile substances at optimized viscosity of the solution $[37,38]$. The formation of discrete particles is hindered when the feeding solution viscosity is too high, which can result in significant losses of volatile components during atomization. On the other hand, low viscous solutions would require a longer time to form a semi-permeable barrier at the beginning of the drying process so that evaporation of essential oils is prevented [22,39]. Furthermore, the total oil content was significantly affected by the type of the encapsulating oil-lavender or peppermint oil. Dramatic differences were observed in samples prepared under the same conditions, varying only the type of the encapsulated oils, especially at a low polymer concentration of $10 \%$. The total content of lavender oil was $5.31 \%$, whereas the peppermint oil retained in the particles was only $1.34 \%$. This could be attributed to the formation of particles with multiple invaginations and indentations, and small volume capacity for oil encapsulation, as seen from the scanning electron microscopy (Figure 1, 
sample PO-2.5-AG-10). This was confirmed by encapsulation efficiency data (19.77\%) suggesting that a great amount of peppermint oil was lost during atomization due to evaporation. The highest encapsulation efficiency $(91.08 \%)$ was observed at sample LO5-MD-20, prepared using maltodextrin and lavender oil, proving the hypothesis that the optimum combination of feeding material and drying conditions is needed for achieving the maximum encapsulation efficiency and oil retention.

\subsection{Surface Content of Essential Oils in the Particles}

The surface oil content of essential oil microparticles is often used as an important tool for assessing their stability [23,40]. In addition, powders with high surface oil content are prone to sticking and cohesion, leading to poor flowability [37]. The surface oil contents of the formulated microparticle models ranged from $0.93 \%$ to $2.07 \%$. The registered low surface oil content is also an indicator of the efficient encapsulation of the oil inside the obtained polymer particles.

\subsubsection{Surface Content of Lavender Oil}

The particle surface oil content was evaluated using gas chromatographic analysis after extraction of the oil from the surface of the microparticles with hexane for $15 \mathrm{~min}$. The lavender oil components content ( $\alpha$-pinene, $\beta$-pinene, 3-octanone, cineole, linalool, camphor, lavender, terpinene-4-ol, menthyl acetate, caryophyllene) was determined. The surface oil content was calculated based on linalool and camphor, which predominate in the composition of lavender oil. The results are presented in Table 3 . The surface content in all the samples is relatively low (ranging from $1.13 \%$ to $2.07 \%$ ) compared to the total content of essential oil in the microparticles, which is a reason to believe that high microencapsulation efficiency has been achieved. The variations between the individual models can be explained by the influence of maltodextrin in some of the compositions as a capsule sealant. With an increase in the amount of maltodextrin, there is a tendency to decrease the surface oil content and priority distribution of the oil in the core of the microparticles.

Table 3. Surface content and total amount of lavender oil in microparticles.

\begin{tabular}{|c|c|c|c|c|}
\hline \multirow[t]{2}{*}{ Sample Code } & \multicolumn{2}{|c|}{$\begin{array}{l}\text { Surface Content of LO in Microparticles } \\
\text { Calculated as Percentage of: }\end{array}$} & \multirow{2}{*}{$\begin{array}{c}\text { Total Amount of } \\
\text { LO, } \\
\%\end{array}$} & \multirow{2}{*}{$\begin{array}{l}\text { Surface Content of LO Relative } \\
\text { to the Total Amount, } \%\end{array}$} \\
\hline & Linalool, \% & Camphor, \% & & \\
\hline LO-5-AG-20 & 0.21 & 0.22 & 10.62 & 2.07 \\
\hline LO-2.5-AG-10 & 0.11 & 0.08 & 5.31 & 1.51 \\
\hline LO-5-AG-MD-15/5 & 0.22 & 0.20 & 10.55 & 1.90 \\
\hline LO-5-AG-MD-10/10 & 0.10 & 0.10 & 8.85 & 1.13 \\
\hline LO-5-AG-MD-5/15 & 0.10 & 0.10 & 7.08 & 1.41 \\
\hline LO-5-MD-20 & 0.10 & 0.10 & 10.80 & 0.93 \\
\hline
\end{tabular}

\subsubsection{Surface Content of Peppermint Oil}

Particle surface oil content was evaluated using gas chromatographic analysis after extraction of the oil from the surface of the microparticles with hexane for $15 \mathrm{~min}$. The quantitative content of the components of the oil ( $\alpha$-pinene, $\beta$-pinene, 3-octanone, limonen, linalool, camphor, menthone, menthol, menthyl acetate, caryophyllene) was determined. The surface content of peppermint oil in the microparticles was calculated based on menthol, which predominated in the composition of peppermint oil. The obtained results are presented in Table 4.

According to the obtained results, the surface oil content was relatively low (around $1.5 \%$ from the total oil content). An insignificant difference between the two evaluated sample models was observed. 
Table 4. Surface content and total amount of peppermint oil in microparticles.

\begin{tabular}{cccc}
\hline Sample Code & $\begin{array}{c}\text { Surface Content of PO in } \\
\text { Microparticles Calculated } \\
\text { as Percentage of: } \\
\text { Menthol, } \%\end{array}$ & $\begin{array}{c}\text { Total Amount of PO, } \\
\%\end{array}$ & $\begin{array}{c}\text { Surface Content of } \\
\text { PO Relative to the } \\
\text { Total Amount, \% }\end{array}$ \\
\hline PO-5-AG-20 & 0.11 & 7.18 & 1.53 \\
PO-2.5-AG-10 & 0.02 & 1.34 & 1.49 \\
\hline
\end{tabular}

\subsection{Moisture Content}

The moisture content of the microparticles (Table 5) ranged from 3.65 to $5.51 \%$. The values obtained were similar to those reported by other research groups working on spray-drying of essential oils: $1.70-4.16 \% ; 1.20 \_2.70 \%[24,41]$.

Table 5. Moisture content and flow properties of the developed microparticles $(n=3)$.

\begin{tabular}{cccc}
\hline Sample Code & $\begin{array}{c}\text { Moisture Content, } \\
\% \pm \text { SD }\end{array}$ & $\begin{array}{c}\text { Angle of Repose, } \\
{ }^{ \pm} \text {SD }\end{array}$ & $\begin{array}{c}\text { Hausner Ratio } \\
\pm \text { SD }\end{array}$ \\
\hline LO-5-AG-20 & $5.51 \pm 0.23$ & $49.48 \pm 0.24$ & $1.875 \pm 0.03$ \\
LO-2.5-AG-10 & $4.39 \pm 0.10$ & $53.57 \pm 0.51$ & $1.852 \pm 0.05$ \\
LO-5-AG-MD-15/5 & $4.05 \pm 0.06$ & $50.16 \pm 0.68$ & $1.816 \pm 0.08$ \\
LO-5-AG-MD-10/10 & $3.74 \pm 0.12$ & $45.78 \pm 1.08$ & $1.592 \pm 0.06$ \\
LO-5-AG-MD-5/15 & $3.65 \pm 0.14$ & $43.55 \pm 0.40$ & $1.518 \pm 0.10$ \\
LO-5-MD-20 & $3.58 \pm 0.03$ & $39.00 \pm 0.99$ & $1.432 \pm 0.07$ \\
PO-5-AG-20 & $4.78 \pm 0.18$ & $46.61 \pm 1.13$ & $1.687 \pm 0.02$ \\
PO-2.5-AG-10 & $4.36 \pm 0.21$ & $44.96 \pm 1.37$ & $1.514 \pm 0.01$ \\
\hline
\end{tabular}

The effect of process variables on particle moisture has been thoroughly studied and verified by numerous researchers. The main spray-drying parameters that influence the product moisture content are the inlet temperature, air-drying temperature, and feed rate [42]. In the present study, we examined the effect of the wall material type and concentration. The residual moisture in the formulated powders increased when a higher concentration of Arabic gum was used. This may be due to the large-sized molecules of the polymer, which prevent water diffusion during spray-drying. In addition, higher amounts of encapsulating material are usually associated with a shorter time to form the capsule shell formation, which also contributes to hindered water diffusion [43]. Furthermore, there was a clear trend towards reduced moisture content when the concentration of maltodextrin was increased. That was also observed in a study by Fasaeli et al. and could be explained by the fact that maltodextrins with low dextrose equivalent $(\mathrm{DE}=10-15)$, as the type used for the present work, are less hygroscopic than higher DE maltodextrins and have a lower tendency to water retention [44].

\subsection{Flowability Study}

Powder flow properties are essential for the further processing of the prepared microparticles into solid dosage forms (tablets or capsules). The flowability of the formulated particle models was investigated by determining the angle of repose and the Hausner ratio. The angle of repose (Table 5) was greater than $35^{\circ}$, indicating fair to passable flow properties [45]. A gradual decrease in the angle of repose was noticed with the addition of maltodextrin as a wall material. Moreover, the higher the maltodextrin concentration, the smaller the angle of repose. The smallest angle of repose $\left(39^{\circ}\right)$ related to satisfactory flowability was achieved in the sample containing maltodextrin as the only encapsulating polymer. Probably, that was due to the lower moisture content of the microparticles. On the other hand, the lower surface oil content of the models increased the stickiness between the microparticles, which probably led to a deterioration of the flowability. 


\section{Conclusions}

In this study, lavender and peppermint essential oils were successfully encapsulated by emulsification with Arabic gum, Tween 80 and Span 80, and a subsequent spray-drying process at $170{ }^{\circ} \mathrm{C}$ temperature, $35 \mathrm{~m}^{3} / \mathrm{h}$ aspiration flow, and $7.5 \mathrm{~mL} / \mathrm{min}$ feed flow. The particles obtained had irregular surfaces and mean diameters from 2.41 to $5.99 \mu \mathrm{m}$. The process parameters that mainly affected the yields, particle size, and oil content were the type and concentration of the wall material. A polymer concentration of $20 \%$ was required for higher oil retention in the particles. The results show that Arabic gum alone could not form a continuous and stable film around the oil droplets. The addition of maltodextrin as a second polymer proved to be a successful approach for further sealing the walls of the resulting solid structures and improving their morphological characteristics. From the varied ratios between Arabic gum and maltodextrin, 3:1 could be outlined as optimal, resulting in particles with high encapsulation efficiency and a high total essential oil content of $10.55 \%$. Our study has demonstrated that the encapsulation of lavender and peppermint oils in Arabic gum/maltodextrin microparticles by spray-drying represents a feasible approach for the conversion of liquid materials into solids with satisfactory flowability for further use in powder technology.

Author Contributions: Conceptualization, B.P.; methodology, B.P., P.K. and Y.U.; writing—original draft preparation, B.P.; writing-review and editing, P.K. and Y.U. All authors have read and agreed to the published version of the manuscript.

Funding: This research was funded by Medical University of Plovdiv, Research Fund through grant number HO-15/2015.

Institutional Review Board Statement: Not applicable.

Informed Consent Statement: Not applicable.

Data Availability Statement: The data presented in this study are available on request from the corresponding author.

Conflicts of Interest: The authors declare no conflict of interest.

Sample Availability: Samples of the compounds are available from the authors.

\section{References}

1. Hammer, K.A.; Carson, C.F.; Riley, T.V. Antimicrobial activity of essential oils and other plant extracts. J. Appl. Microbiol. 1999, 86, 985-990. [CrossRef] [PubMed]

2. Sharmeen, J.; Mahomoodally, F.; Zengin, G.; Maggi, F. Essential Oils as Natural Sources of Fragrance Compounds for Cosmetics and Cosmeceuticals. Molecules 2021, 26, 666. [CrossRef] [PubMed]

3. Aljaafari, M.; AlAli, A.; Baqais, L.; Alqubaisy, M.; AlAli, M.; Molouki, A.; Ong-Abdullah, J.; Abushelaibi, A.; Lai, K.-S.; Lim, S.-H. An Overview of the Potential Therapeutic Applications of Essential Oils. Molecules 2021, 26, 628. [CrossRef] [PubMed]

4. Caprari, C.; Fantasma, F.; Divino, F.; Bucci, A.; Iorizzi, M.; Naclerio, G.; Ranalli, G.; Saviano, G. Chemical Profile, In Vitro Biological Activity and Comparison of Essential Oils from Fresh and Dried Flowers of Lavandula angustifolia L. Molecules 2021, 26, 5317. [CrossRef]

5. Wilson, T.; Poulson, A.; Packer, C.; Carlson, R.; Buch, R. Essential Oil Profile and Yield of Corolla, Calyx, Leaf, and Whole Flowering Top of Cultivated Lavandula angustifolia Mill. (Lamiaceae) from Utah. Molecules 2021, 26, 2343. [CrossRef] [PubMed]

6. Valková, V.; Ďúranová, H.; Galovičová, L.; Vukovic, N.; Vukic, M.; Kačániová, M. In Vitro Antimicrobial Activity of Lavender, Mint, and Rosemary Essential Oils and the Effect of Their Vapours on Growth of Penicillium spp. in a Bread Model System. Molecules 2021, 26, 3859. [CrossRef]

7. Koulivand, P.H.; Ghadiri, M.K.; Gorji, A. Lavender and the Nervous System. Evidence-Based Complement. Altern. Med. 2013, 2013, 681304. [CrossRef] [PubMed]

8. Masomeh, L.; Narges, M.; Hassan, R.; Hadi, A. Peppermint and Its Functionality: A Review. Arch. Clin. Microbiol. 2017,8 , 54. [CrossRef]

9. Chumpitazi, B.P.; Kearns, G.L.; Shulman, R.J. Review article: The physiological effects and safety of peppermint oil and its efficacy in irritable bowel syndrome and other functional disorders. Aliment. Pharmacol. Ther. 2018, 47, 738-752. [CrossRef]

10. Mogosan, C.; Vostinaru, O.; Oprean, R.; Heghes, C.; Filip, L.; Balica, G.; Moldovan, R.I. A Comparative Analysis of the Chemical Composition, Anti-Inflammatory, and Antinociceptive Effects of the Essential Oils from Three Species of Mentha Cultivated in Romania. Molecules 2017, 22, 263. [CrossRef] [PubMed] 
11. Wu, Z.; Tan, B.; Liu, Y.; Dunn, J.; Guerola, P.M.; Tortajada, M.; Cao, Z.; Ji, P. Chemical Composition and Antioxidant Properties of Essential Oils from Peppermint, Native Spearmint and Scotch Spearmint. Molecules 2019, 24, 2825. [CrossRef] [PubMed]

12. Eslahi, H.; Fahimi, N.; Sardarian, A.R. Chapter 4. Chemical Composition of Essential Oils. In Essential Oils in Food Processing: Chemistry, Safety and Applications, 1st ed.; Hashemi, M.B., Mousavi Khaneghah, A., de Souza Sant'Ana, A., Eds.; John Wiley \& Sons Ltd.: New Jersey, NJ, USA, 2017; pp. 119-171. [CrossRef]

13. Carvalho, I.T.; Estevinho, B.N.; Santos, L. Application of microencapsulated essential oils in cosmetic and personal healthcare products-A review. Int. J. Cosmet. Sci. 2016, 38, 109-119. [CrossRef]

14. Delfiya, D.A.; Thangavel, K.; Natarajan, N.; Kasthuri, R.S.; Kailappan, R. Microencapsulation of Turmeric Oleoresin by Spray Drying and In Vitro Release Studies of Microcapsules. J. Food Process. Eng. 2015, 38, 37-48. [CrossRef]

15. Jovanović, A.; Lević, S.; Pavlović, V.; Marković, S.; Pjanović, R.; Đorđević, V.; Nedović, V.; Bugarski, B. Freeze vs. Spray Drying for Dry Wild Thyme (Thymus serpyllum L.) Extract Formulations: The Impact of Gelatin as a Coating Material. Molecules 2021, 26, 3933. [CrossRef] [PubMed]

16. Hijo, A.T.; Costa, J.M.; Silva, E.K.; Azevedo, V.M.; Yoshida, M.I.; Borges, S. Physical and Thermal Properties of Oregano (O riganum vulgare L.) Essential Oil Microparticles. J. Food Process. Eng. 2015, 38, 1-10. [CrossRef]

17. Gharsallaoui, A.; Roudaut, G.; Chambin, O.; Voilley, A.; Saurel, R. Applications of spray-drying in microencapsulation of food ingredients: An overview. Food Res. Int. 2007, 40, 1107-1121. [CrossRef]

18. Huang, H.-J.; Yuan, W.-K.; Chen, X.D. Microencapsulation Based on Emulsification for Producing Pharmaceutical Products: A Literature Review. Dev. Chem. Eng. Miner. Process. 2008, 14, 515-544. [CrossRef]

19. Ferreira, S.; Malacrida, C.R.; Nicoletti, V.R. Influence of Emulsification Methods and Spray Drying Parameters on the Microencapsulation of Turmeric Oleoresin. Emir. J. Food Agric. 2019, 31, 491-500. [CrossRef]

20. Lammari, N.; Louaer, O.; Meniai, A.H.; Elaissari, A. Encapsulation of Essential Oils via Nanoprecipitation Process: Overview, Progress, Challenges and Prospects. Pharmaceutics 2020, 12, 431. [CrossRef]

21. Asbahani, A.E.; Miladi, K.; Badri, W.; Sala, M.; Addi, E.A.; Casabianca, H.; Mousadik, A.E.; Hartmann, D.; Jilale, A.; Renaud, F.N.R.; et al. Essential oils: From extraction to encapsulation. Int. J. Pharm. 2015, 483, 220-243. [CrossRef] [PubMed]

22. Adamiec, J. Moisture Sorption Characteristics of Peppermint Oil Microencapsulated by Spray Drying. Dry. Technol. 2009, 27, 1363-1369. [CrossRef]

23. Baranauskienè, R.; Bylaite, E.; Žukauskaitè, J.; Venskutonis, R.P. Flavor Retention of Peppermint (Mentha piperita L.) Essential Oil Spray-Dried in Modified Starches during Encapsulation and Storage. J. Agric. Food Chem. 2007, 55, 3027-3036. [CrossRef] [PubMed]

24. Adamiec, J.; Kalemba, D. Analysis of Microencapsulation Ability of Essential Oils during Spray Drying. Dry. Technol. 2006, 24, 1127-1132. [CrossRef]

25. Glomm, W.; Molesworth, P.; Sandru, E.; Truong, L.; Brunsvik, A.; Johnsen, H. Microencapsulation of Peppermint Oil by Complex Coacervation and Subsequent Spray Drying Using Bovine Serum Albumin/Gum Acacia and an Oxidized Starch Crosslinker. Appl. Sci. 2021, 11, 3956. [CrossRef]

26. Burhan, A.M.; Abdel-Hamid, S.M.; Soliman, M.E.; Sammour, O.A. Optimisation of the microencapsulation of lavender oil by spray drying. J. Microencapsul. 2019, 36, 250-266. [CrossRef] [PubMed]

27. Bertolini, A.C.; Siani, A.C.; Grosso, C.R.F. Stability of Monoterpenes Encapsulated in Gum Arabic by Spray-Drying. J. Agric. Food Chem. 2001, 49, 780-785. [CrossRef] [PubMed]

28. Hassani, M.; Hasani, S. Nano-encapsulation of thyme essential oil in chitosan-Arabic gum system: Evaluation of its antiox-idant and antimicrobial properties. Trends Phytochem. Res. 2018, 2, 75-82.

29. Kaushik, V.; Roos, Y.H. Limonene encapsulation in freeze-drying of gum Arabic-sucrose-gelatin systems. LWT-Food Sci. Technol. 2007, 40, 1381-1391. [CrossRef]

30. Adhikari, B.; Howes, T.; Bhandari, B.R.; Truong, V. Characterization of the Surface Stickiness of Fructose-Maltodextrin Solutions During Drying. Int. J. Food Prop. 2003, 21, 17-34. [CrossRef]

31. Savova, M.; Hristova, V.; Pilicheva, B. Determination of the optimum HLB value of lavender oil—an essential parameter for the development of emulsion formulations. Sci. Work. Union Sci. Bulg. Plovdiv 2017, 21, 229-232.

32. Jaya, S.; Das, H. Effect of maltodextrin, glycerol monostearate and tricalcium phosphate on vacuum dried mango powder properties. J. Food Eng. 2004, 63, 125-134. [CrossRef]

33. Papadakis, S.E.; Gardeli, C.; Tzia, C. Spray Drying of Raisin Juice Concentrate. Dry. Technol. 2006, 24, 173-180. [CrossRef]

34. Roustapour, O.; Hosseinalipour, M.; Ghobadian, B. An Experimental Investigation of Lime Juice Drying in a Pilot Plant Spray Dryer. Dry. Technol. 2006, 24, 181-188. [CrossRef]

35. Quek, S.Y.; Chok, N.K.; Swedlund, P. The physicochemical properties of spray-dried watermelon powders. Chem. Eng. Process. 2007, 46, 386-392. [CrossRef]

36. Jafari, S.M.; Assadpoor, E.; Bhandari, B.; He, Y. Nano-particle encapsulation of fish oil by spray drying. Food Res. Int. 2008, 41, 172-183. [CrossRef]

37. Reineccius, G.A. The Spray Drying of Food Flavors. Dry. Technol. 2004, 22, 1289-1324. [CrossRef]

38. de Barros Fernandes, R.V.; Borges, S.; Botrel, D.A.; Silva, E.K.; Costa, J.M.; Queiroz, F. Microencapsulation of Rosemary Essential Oil: Characterization of Particles. Dry. Technol. 2013, 31, 1245-1254. [CrossRef] 
39. Huynh, T.V.; Caffin, N.; Dykes, G.A.; Bhandari, B. Optimization of the Microencapsulation of Lemon Myrtle Oil Using Response Surface Methodology. Dry. Technol. 2008, 26, 357-368. [CrossRef]

40. Bringas-Lantigua, M.; Expósito-Molina, I.; Reineccius, G.A.; López-Hernández, O.; Pino, J.A. Influence of Spray-Dryer Air Temperatures on Encapsulated Mandarin Oil. Dry. Technol. 2011, 29, 520-526. [CrossRef]

41. Jafari, S.M.; He, Y.; Bhandari, B. Encapsulation of Nanoparticles of d-Limonene by Spray Drying: Role of Emulsifiers and Emulsifying Techniques. Dry. Technol. 2007, 25, 1069-1079. [CrossRef]

42. Finney, J.; Buffo, R.; Reineccius, G. Effects of Type of Atomization and Processing Temperatures on the Physical Properties and Stability of Spray-Dried Flavors. J. Food Sci. 2002, 67, 1108-1114. [CrossRef]

43. Tonon, R.V.; Grosso, C.R.; Hubinger, M.D. Influence of emulsion composition and inlet air temperature on the microencapsulation of flaxseed oil by spray drying. Food Res. Int. 2011, 44, 282-289. [CrossRef]

44. Fazaeli, M.; Emam-Djomeh, Z.; Ashtari, A.K.; Omid, M. Effect of spray drying conditions and feed composition on the physical properties of black mulberry juice powder. Food Bioprod. Process. 2012, 90, 667-675. [CrossRef]

45. Flow Properties and Corresponding Angles of Repose. European Pharmacopoeia; European Pharmacopoeia, 9.0 (Ed.) Section: 2.9.36. Powder flow. Table 2.9.36.-1; Council of Europe: Strasbourg, France, 2016; p. 321. 